\title{
PREPARATION, CHARACTERIZATION AND ANTI-AGEING ACTIVITY OF GASTRODIA ELATA BLUME POLYSACCHARIDE
}

\author{
L. CHEN ${ }^{\mathrm{a}, \mathrm{c}, \mathrm{d}, *}$, Y.P. ZHANG ${ }^{\mathrm{b}}$ and L.X. JIN $\mathrm{JN}^{\mathrm{a}, \mathrm{c}, \mathrm{d}}$ \\ ${ }^{\mathrm{a}}$ Jiangsu Marine Resources Development Research Institute, Huaihai Institute of Technology, 59 Cangwu Road, \\ 222005, Haizhou. China \\ ${ }^{\mathrm{b}}$ Shcool of Chemical Engineering, Dalian University of Technology, 2 Linggong Road, Ganjingzi, 116024, Dalian. \\ China \\ ${ }^{c}$ Jiangsu Key Laboratory of Marine Pharmaceutical Compound Screening, Huaihai Institute of Technology, \\ 222005, Haizhou. China \\ ${ }^{\mathrm{d}}$ Co-Innovation Center of Jiangsu Marine Bio-industry Technology, Huaihai Institute of Technology, 222005, \\ Haizhou. China
}

(Received: 16 September 2017; accepted: 25 January 2018)

\begin{abstract}
Gastrodia elata Blume polysaccharide (GEP) was extracted and then chemically characterised. Its antioxidant activity was evaluated in vitro and in vivo. The results of the in vitro investigation show that GEP consists of glucose with molecular weight of $875185 \mathrm{Da}$ and exhibits high hydroxyl radical scavenging, as well as 2,2-diphenyl-1picrylhydrazyl activity and reducing capacity. For antioxidant activity in vivo, D-galactose-induced-aged mice were orally administered with three different doses of GEP over a period of 6 weeks. The administration of GEP dosedependently increased the body weight gain rates, liver and brain indices, superoxide dismutase and glutathione peroxidase activities, and malondialdehyde levels in the sera and brains of ageing mice. These results suggest that GEP exhibits high antioxidant activity and can retard human ageing associated with free radicals.
\end{abstract}

Keywords: Gastrodia elata Blume, polysaccharide, antioxidant activity, anti-ageing activity

Gastrodia elata Blume (G. elata Bl) belongs to the genus Gastrodia, family Compositae, and is a widely used traditional Chinese herb. G. elata Bl rhizomes are typically used as anticonvulsants, analgesics, sedative, and agent against general paralysis, epilepsy, vertigo, and tetanus (TANG \& EISENBRAND, 1992; JiANG et al., 2010; KwON et al., 2014; Li et al., 2015).

G. elata Bl rhizomes have high water-soluble polysaccharide contents of up to $9.61 \%$ (Liv et al., 2009). CHEN and co-workers (2011) extracted a water-soluble polysaccharide from G. elata $\mathrm{Bl}$ rhizomes by using $\alpha-(1 \rightarrow 4)$ glucan with $\alpha-(1 \rightarrow 4)$ glucosyl branches attached to the O-6 of branching points. Ming and co-workers (2012) also prepared G. elata Bl polysaccharide mainly containing glucose molecules with $(1 \rightarrow 4)-\alpha$-D-glucan main chains that are occasionally branched with a-1,6 glycosidic linkages. G. elata $\mathrm{Bl}$ polysaccharides have many important biological activities, such as enhancing immunity, up-regulating protein expressions, disrupting pancreatic cancer cell growth, lowering fat levels, free radical scavenging, preventing hypertension, and protecting the retina (MiAo \& SHEN, 2006; LiU et al., 2009; Ming et al., 2012). However, the anti-ageing activities of the polysaccharide from G. elata Bl polysaccharide (GEP) are rarely reported.

In this study, GEP was extracted with hot water, and the anti-ageing activities of GEP in rats were investigated.

\footnotetext{
* To whom correspondence should be addressed.

Phone: +8651885585003; fax: +8651885585002; e-mail: chenlhhit@sina.com
}

0139-3006 @ 2018 Akadémiai Kiadó, Budapest 


\section{Materials and methods}

\subsection{Ethics statement}

This study was approved by the ethics committee of Huahai Institute of Technology, China (ECHHIT20150528). All procedures were performed in compliance with relevant laws and institutional guidelines.

\subsection{Materials}

Dried G. elata Bl rhizomes were purchased from Shandong Dingli Rubber Industry Co., Ltd. (Shandong, China). Standard monosaccharide samples (glucose, xylose, and mannose) were obtained from Sigma Chemical Co. (St. Louis, MO, USA). All other reagents were of analytical grade.

\subsection{GEP preparation}

Dried G. elata B1 rhizomes were pulverised and sifted through an 80-mesh sieve to yield fine powder. The obtained powder was soaked in distilled water under agitation at room temperature $\left(\sim 20{ }^{\circ} \mathrm{C}\right)$ for $1 \mathrm{~h}$ to produce a suspension with $\sim 1 \%(\mathrm{w} / \mathrm{v})$ concentration. The resulting suspension was placed in a thermostatic water bath at $90{ }^{\circ} \mathrm{C}$ for $4 \mathrm{~h}$ and then centrifuged at $5000 \times g$ for $15 \mathrm{~min}$. The proteins in the resulting supernatant were separated with the Sevag method, precipitated with three volumes of absolute ethanol, filtered using a Whatman GF/A filter paper, and finally freeze-dried.

\subsection{GEP characterisation}

The total sugar, protein, and ash contents in the products were determined with phenolsulphuric acid colorimetric method, Kjeldahl method, and the method described by Hou (2004), respectively. The Fourier transform infrared (FTIR) spectra of the representative product samples were obtained from the $\mathrm{KBr}$ pellets by using a Nicolet Nexus FTIR 470 spectrophotometer over a wavelength range of 400-4000 $\mathrm{cm}^{-1}$. UV spectra were recorded on a UV spectrometer (Spectra Test, Germany). The molecular weights (MWs) of the GEP were determined by high performance gel filtration chromatography (LC-10A, Shimadzu, Japan) in which an Ultrahydrogel size exclusion column (LKB-Prodokter, AB, Bromma, Switzerland) and high-sensitive refractive index detector, Model ERC-7515 A (ERC Inc., Japan) were used. The GEP were eluted with $0.1 \mathrm{~N} \mathrm{NaNO}_{3}$ at a flow rate of $0.9 \mathrm{ml} \mathrm{min}^{-1}$. Pullulan standards (P20-P800, JM Science, Inc., NY, USA) were used as molecular weight standard. The GEP was hydrolysed according to the methods described by SHENG and co-workers (2007). The monosaccharide compositions of the obtained AMP were assayed by and ion chromatograph (ICS-5000, Dionex, USA) in which a carbohydrate Column (CarboPac PA20, Dionex, USA) and pulse amperes detector (Dionex, USA) were used. The monosaccharides of AMP were eluted with mobile phase at a flow rate of $0.5 \mathrm{ml} \mathrm{min}$. The composition and conditions of mobile phase are as follows: $0-21.1 \mathrm{~min}(97.4 \%$ of water and $2.6 \%$ of $250 \mathrm{mM} \mathrm{NaOH})$; $21.1-30 \mathrm{~min}(92.4 \%$ of water, $2.6 \%$ of $250 \mathrm{mM} \mathrm{NaOH}$, and $5.0 \%$ of $\mathrm{NaAc}) ; 30-50 \mathrm{~min}(20 \%$ of water and $80 \%$ of $250 \mathrm{mM} \mathrm{NaOH})$. 


\subsection{Animals and treatment}

A total of 60 Kunming mice were purchased from Tumor Hospital Experimental Animal Center of Nanjing Medical University. The Kunming mice ( 30 males and 30 females) were 8 weeks old and had an average weight of 19-21 g. The mice were maintained under the following environmental conditions: temperature of $25{ }^{\circ} \mathrm{C}$, humidity of $50 \%$, and light conditions of 12:12 h light: dark cycle for 1 week before the experimental protocol. During the experimental period, the mice were provided with rodent laboratory chow and tap water ad libitum.

The mice were randomly divided into five groups. In particular, 12 mice were included in the normal control group (NCG), 12 mice in the D-galactose (D-gal) model control group (MCG), and 12 mice each in the 1,2, and $3 \mathrm{~g} \mathrm{~kg}^{-1}$ GEP-treated groups. For the establishment of the ageing model mice, D-gal saline $(0.9 \%)$ solution with a dose of $100 \mathrm{~g} \mathrm{~kg}^{-1}$ body weight was injected into the back of each mouse once a day for 6 weeks. For the GEP-treated groups, the mice were intragastrically administrated with GEP with doses of 1,2 , or $3 \mathrm{~g} \mathrm{~kg}^{-1} \mathrm{BW}$ day $^{-1}$. For the NCG, the mice received subcutaneous injection of sterile saline instead of the same volume of D-gal solution. For the MCG group, the mice received normal diet without GEP.

One day after the last drug administration, the mice were weighed and sacrificed through cervical dislocation. Blood samples from the retrobulbar venous plexus of the sacrificed mice were centrifuged at $10000 \times \mathrm{g}$ and $4{ }^{\circ} \mathrm{C}$ for $15 \mathrm{~min}$ to yield blood sera. The sera were stored at $-80{ }^{\circ} \mathrm{C}$ for further assay. The brains and livers were removed immediately, weighed and mixed with $0.9 \%$ ice-cold $\mathrm{NaCl}$ solution to yield $10 \%$ homogenates, which were centrifuged at $4000 \times g$ and $4{ }^{\circ} \mathrm{C}$ for $15 \mathrm{~min}$. The resulting supernatants were kept at $-80{ }^{\circ} \mathrm{C}$ for biochemical analysis.

\subsection{Antioxidant activities}

The reducing capacity of GEP was determined according to the methods of QIAO and coworkers (2009). GEP ( $1 \mathrm{~g}$ ) was mixed with $1.0 \mathrm{ml}$ of $0.2 \mathrm{M}$ phosphate buffer (pH 6.6) and 1.0 $\mathrm{ml}$ of $1 \%(\mathrm{w} / \mathrm{v})$ potassium ferricyanide, and then incubated at $50{ }^{\circ} \mathrm{C}$ for $20 \mathrm{~min}$ before it was cooled at room temperature. Briefly, $1 \mathrm{ml}$ of trichloroacetic acid $(10 \%, \mathrm{w} / \mathrm{v})$ and $0.2 \mathrm{ml}$ of fresh ferric trichloride $(0.1 \%, \mathrm{w} / \mathrm{v})$ were added to the reaction mixture. The resulting mixture was shaken, and its absorbance was assayed at $700 \mathrm{~nm}$ against a blank sample (water instead of GEP) after $10 \mathrm{~min}$. The absorbance of the reaction mixture indicates the reducing capacity of the sample.

$$
\text { Reducing capacity }=\left(A_{1}-A_{2}\right)
$$

where $A_{1}$ is the absorbance of the sample and $A_{2}$ is the absorbance of the sample under conditions similar to those of $A_{1}$ except that water was used instead of ferric trichloride solution.

The hydroxyl radical scavenging activity (HRSA) of the GEP was determined according to the previously described methods (ANDREws, 1986). The HRSA of GEP was calculated as follows:

$$
\operatorname{HRSA}(\%)=\frac{A_{1}-A_{2}}{A_{1}-A_{0}} \times 100
$$

where $A_{0}$ is the absorbance of the reagent blank, $A_{1}$ is the absorbance of the positive control, and $A_{2}$ is the absorbance of the sample. 
2,2-Diphenyl- $\beta$-picrylhydrazyl (DPPH) radical scavenging activity (DRSA) was assayed according to the method of QIAO and co-workers (2009). Briefly, $0.2 \mathrm{ml}$ of $400 \mu \mathrm{mol} \mathrm{l}{ }^{-1}$ DPPH free radical (DPPH•) in dehydrated alcohol was added to $1.0 \mathrm{ml}$ of GEP solution. Afterwards, $2.0 \mathrm{ml}$ of distilled water was added to the mixture. The resulting mixture was shaken and allowed to stand at room temperature in the dark for $30 \mathrm{~min}$. The absorbance was assayed at $517 \mathrm{~nm}$ against a blank standard (distilled water instead of GEP and DPPH• solutions). Low absorbance corresponded to high free-radical scavenging activity. The percentage of DRSA was calculated by using the following equation:

$$
\operatorname{DRSA}(\%)=\frac{A_{0}-\left(A_{1}-A_{2}\right)}{A_{0}} \times 100
$$

where $A_{0}$ is the absorbance of the control (distilled water instead of GEP), $A_{1}$ is the absorbance of the sample, and $A_{2}$ is the absorbance of the sample obtained under conditions similar to those in $A_{1}$ except that distilled water was used instead of DPPH• solution.

\subsection{Anti-ageing activities}

The activities of superoxide dismutase (SOD) and glutathione peroxidase (GSH-Px) and level of malondialdehyde (MDA) in the supernatants of the tissue homogenates and sera were determined using commercially available kits. The assays were performed at $4{ }^{\circ} \mathrm{C}$ and according to the instructions provided by the manufacturers of the kits.

\subsection{Statistical analysis}

Data were presented as mean $\pm \mathrm{SD}$, and ANOVA was performed to compare the means of the two groups. Statistical significance at $95 \%$ probability level was set at $\mathrm{P}<0.05$.

\section{Results and discussion}

\subsection{Product characterisation}

Total sugar, protein, and ash contents in the GEP product were 91.3\%, 5.9\%, and 2.7\%, respectively, indicating that the GEP could be glycoproteins. The GEP samples were watersoluble white powders. The FTIR spectra of the GEP exhibited peaks at $\sim 3410 \mathrm{~cm}^{-1}(\mathrm{O}-\mathrm{H})$, $\sim 1380 \mathrm{~cm}^{-1}$ (symmetrical deformations of $-\mathrm{CH}_{3}$ and $-\mathrm{CH}_{2}$ ), $\sim 1030 \mathrm{~cm}^{-1}$ (stretching vibrations of the $\mathrm{C}-\mathrm{O}-\mathrm{C}$ molecules in the glucose circle), and $\sim 1630 \mathrm{~cm}^{-1}$ (special absorbance peaks of the aldehydes in the GEP) (Fig. 1). The UV spectra of the GEP products exhibited two peaks at 200-280 nm (Fig. 2), indicating that the GEP product contains proteins. By contrast, the HPLC spectra of the GEP products displayed only one peak at $14.10 \mathrm{~min}$, indicating that the GEP only contained one type of polysaccharide with MW of $107845 \mathrm{Da}$ (Fig. 3). Furthermore, the result of monosaccharide composition analysis with gas chromatography indicated that the GEP only contained glucose (Fig. 4), and thus is consistent with the findings of previous reports (CHEN et al., 2011; Ming et al., 2012). 


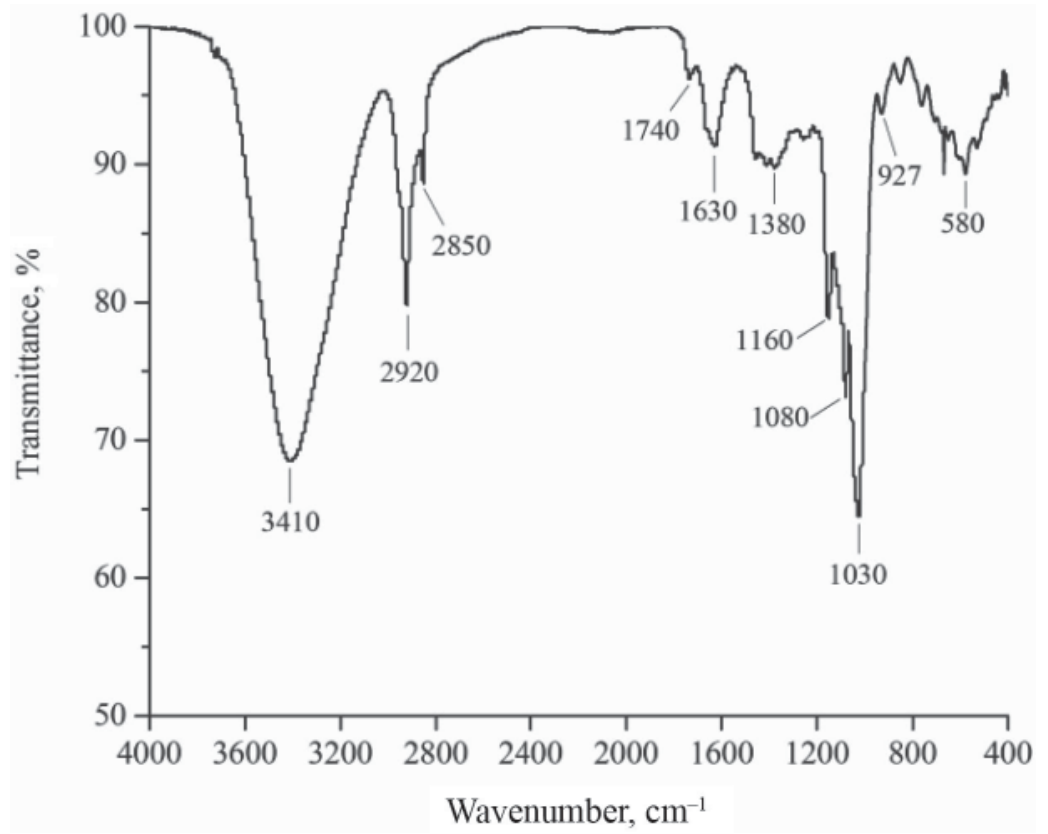

Fig. 1. FT-IR spectra of Gastrodia elata Blume polysaccharide

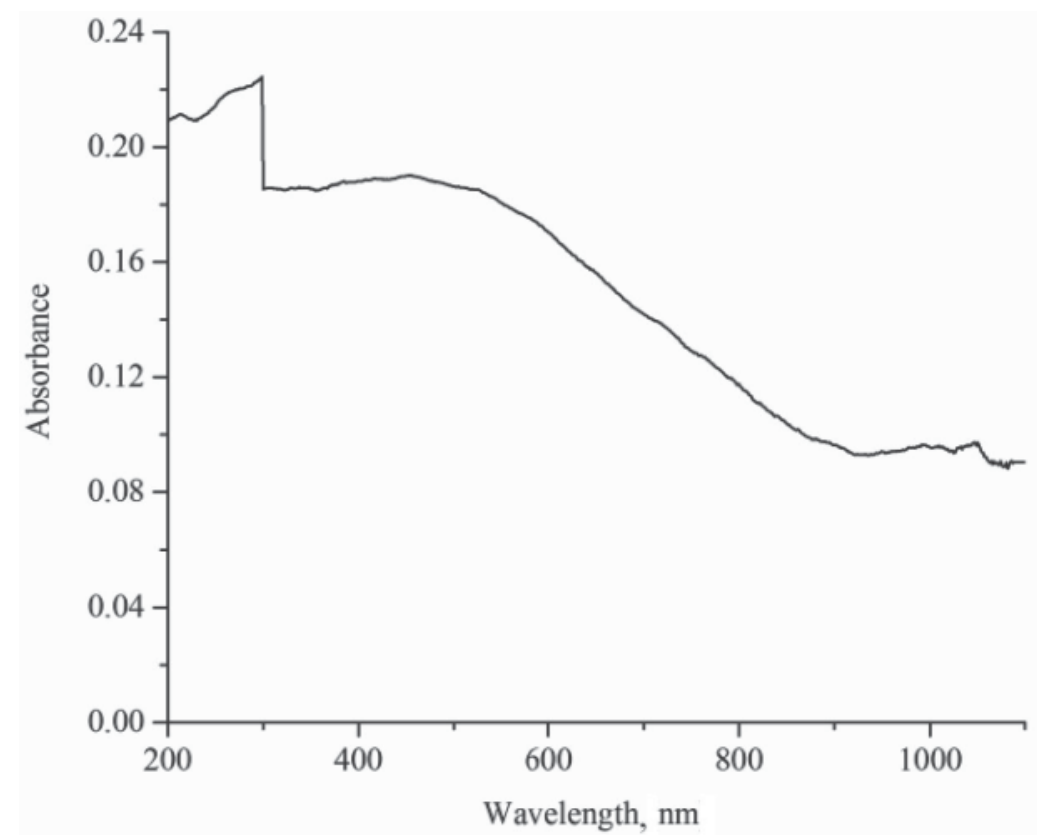

Fig. 2. Ultraviolet visible spectrum of Gastrodia elata Blume polysaccharide 


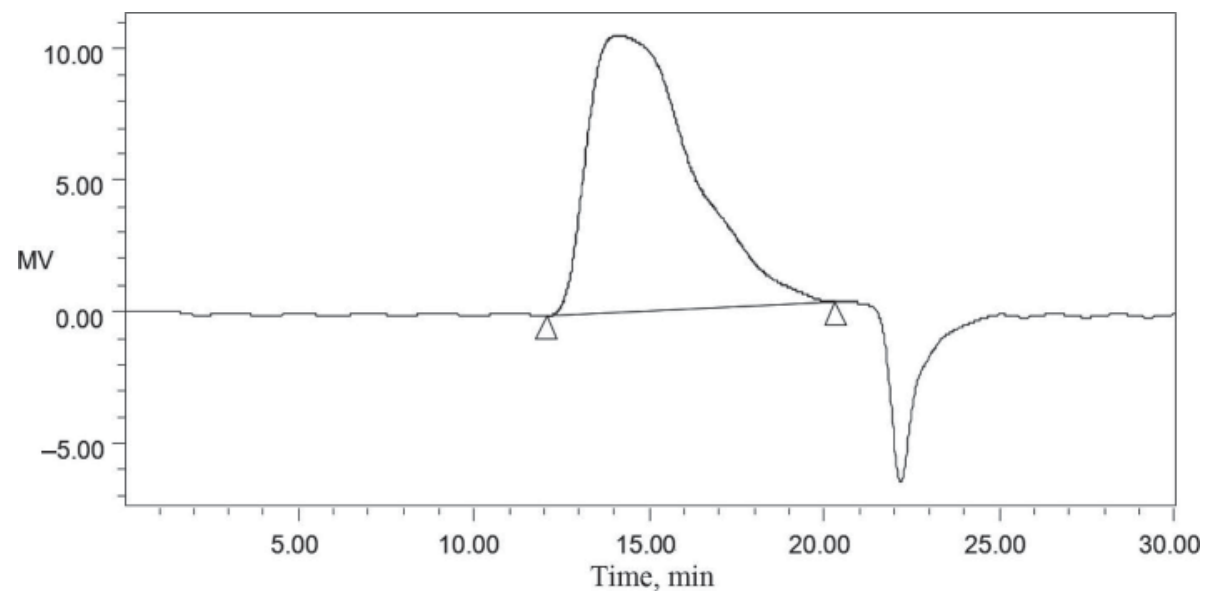

Fig. 3. HPLC spectra of Gastrodia elata Blume polysaccharide

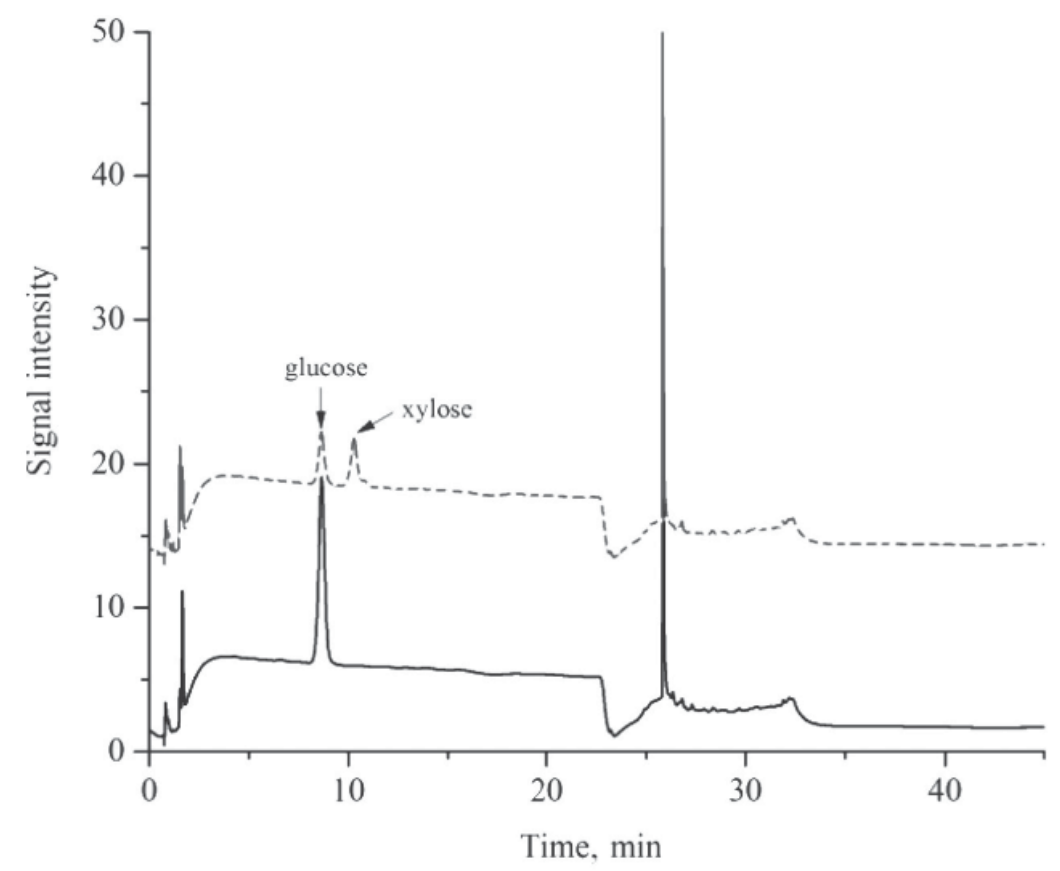

Fig. 4. IC spectra of the sugar composition of Gastrodia elata Blume polysaccharide _

\subsection{Antioxidant activity of GEP}

Hydroxyl radical $(\mathrm{HO} \bullet)$ has the highest activity among free radicals, and DPPH • is a relatively stable radical. Both types of free radicals can attack biological molecules, such as lipids, proteins, enzymes, DNA, and RNA, leading to cell or tissue injury (QIAO et al., 2009; ZHANG 
et al., 2017). Furthermore, they are widely used to evaluate the scavenging activity of some antioxidants (YAO et al., 2013). The HRSA and DRSA of the GEP are shown in Figure 5A. The scavenging activities of GEP increased dose-dependently. At $200 \mathrm{mg} \mathrm{ml}^{-1}$ concentration, the HRSA and DRSA of the GEP were $94.56 \%$ and $84.21 \%$, respectively, indicating that the GEP had high radical-scavenging activities. Reducing capacity is positively correlated to antioxidant activity and is thus important in the evaluation of antioxidant activities (DuH et al., 1999). The reducing capacity of GEP is shown in Figure 5B. At concentrations of 6.25, $12.5,25,50,100$, and $200 \mathrm{mg} \mathrm{ml}^{-1}$, the absorbance values were $0.16,0.44,0.62,0.77$, and 0.87 , respectively. These data suggested the role of reducing capacity in antioxidation.
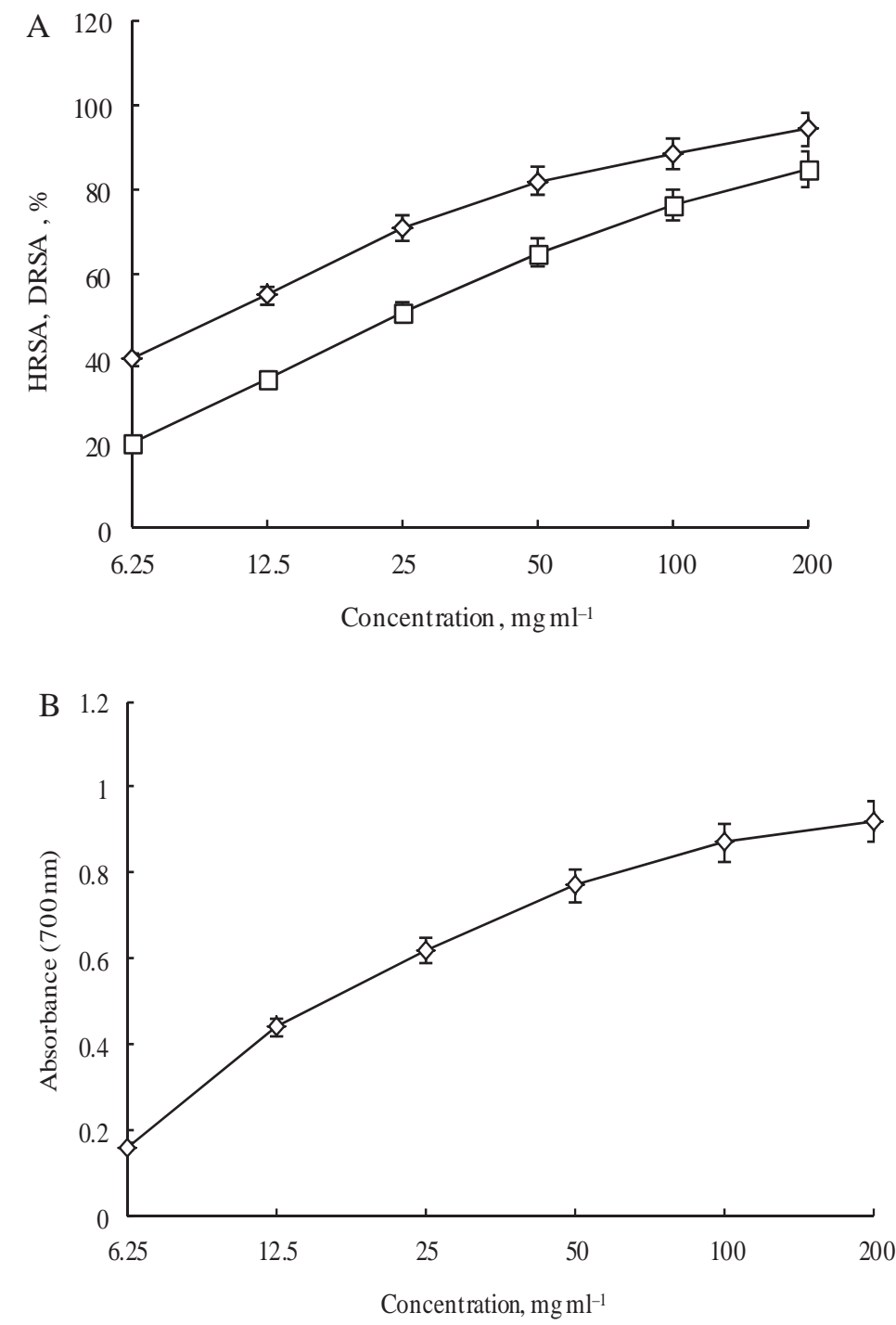

Fig. 5. Antioxidant activities of Gastrodia elata Blume polysaccharide. Bars represent the standard deviation. Data are shown as mean $\pm \mathrm{SD}(\mathrm{n}=3)$

A: $\diamond$ : HRSA; $\square-$ : DRSA; B: reducing capacity of GEP 


\subsection{Anti-ageing activity of GEP}

As shown in Table 1, the gains in body weights of and amounts of food consumed by mice in the intragastric D-gal administration group decreased significantly compared with those in the normal control group $(\mathrm{P}<0.05)$. However, the intragastric administration of GEP dosedependently increased body weight gain and food intake of each mouse $(\mathrm{P}<0.05)$. The intragastric administration of the D-gal group showed significantly decreased liver and brain indices compared with the normal control group $(\mathrm{P}<0.05)$. Nevertheless, the liver and brain indices of mice in GEP-treated groups were higher than those in the MCG $(\mathrm{P}<0.05)$. Similarly, LI and co-workers (2016) reported that GEP up-regulated the expressions of brain-derived neurotrophic factor and stem cell factor protein in caudate putamen of focal cerebral ischemia rats. These findings indicated that GEP can significantly improve the liver and brain indices of mice.

Table 1. Body weight gain rate (BWGR), food intake (FI), liver and brain indices, activities of SOD and GSH-Px, and level of MDA in the serum and brain of ageing mice for normal control group (NCG), D-gal model control group (MCG) and Gastrodia elata polysaccharide (GEP).

\begin{tabular}{|c|c|c|c|c|c|}
\hline Parameters & NCG & D-gal MCG & $\operatorname{GEP}\left(1 \mathrm{~g} \mathrm{~kg}^{-1}\right)$ & $\operatorname{GEP}\left(2 \mathrm{~g} \mathrm{~kg}^{-1}\right)$ & $\operatorname{GEP}\left(3 \mathrm{~g} \mathrm{~kg}^{-1}\right)$ \\
\hline BWGR (g week ${ }^{-1}$ ) & $3.91 \pm 0.68^{d}$ & $1.41 \pm 0.38^{\mathrm{a}}$ & $2.36 \pm 0.39^{b}$ & $2.89 \pm 0.56^{\mathrm{c}}$ & $2.91 \pm 0.54^{\mathrm{c}}$ \\
\hline FI $\left(\mathrm{g} \mathrm{week}^{-1}\right)$ & $39.51 \pm 2.07^{\mathrm{d}}$ & $21.09 \pm 1.48^{\mathrm{a}}$ & $25.86 \pm 1.64^{\mathrm{b}}$ & $34.72 \pm 1.72^{\mathrm{c}}$ & $35.121 \pm 1.76^{\mathrm{c}}$ \\
\hline Liver index $\left(\mathrm{mg} \mathrm{g}^{-1}\right)$ & $38.92 \pm 1.38^{\mathrm{c}}$ & $28.75 \pm 0.86^{\mathrm{a}}$ & $33.72 \pm 1.08^{\mathrm{b}}$ & $38.31 \pm 1.19^{\mathrm{c}}$ & $44.82 \pm 1.34^{\mathrm{d}}$ \\
\hline Brain index $\left(\mathrm{mg} \mathrm{g}^{-1}\right)$ & $10.41 \pm 0.42^{b}$ & $8.92 \pm 0.23^{\mathrm{a}}$ & $10.43 \pm 0.34^{\mathrm{b}}$ & $11.62 \pm 0.41^{\mathrm{c}}$ & $12.34 \pm 0.42^{\mathrm{d}}$ \\
\hline Serum SOD $\left(\mathrm{U} \mathrm{mg}^{-1}\right)$ & $308.41 \pm 15.62^{b}$ & $186.33 \pm 12.87^{\mathrm{a}}$ & $293.54 \pm 14.34^{\mathrm{b}}$ & $304.14 \pm 15.52^{b}$ & $306.46 \pm 14.69^{b}$ \\
\hline Serum GSH-Px $\left(\mathrm{U} \mathrm{mg}^{-1}\right)$ & $80.13 \pm 6.02^{\mathrm{c}}$ & $33.55 \pm 3.46^{\mathrm{a}}$ & $51.37 \pm 3.66^{\mathrm{b}}$ & $74.05 \pm 4.52^{\mathrm{c}}$ & $75.52 \pm 4.74^{\mathrm{c}}$ \\
\hline Serum MDA (U mg $\left.{ }^{-1}\right)$ & $9.47 \pm 0.32^{\mathrm{c}}$ & $14.92 \pm 0.62^{\mathrm{a}}$ & $10.91 \pm 0.48^{\mathrm{b}}$ & $9.37 \pm 0.35^{\mathrm{c}}$ & $9.26 \pm 0.29^{c}$ \\
\hline Brain SOD $\left(\mathrm{U} \mathrm{mg}^{-1}\right)$ & $48.13 \pm 2.51^{\mathrm{c}}$ & $23.46 \pm 1.53^{\mathrm{a}}$ & $35.06 \pm 2.14^{\mathrm{b}}$ & $47.06 \pm 2.57^{\mathrm{c}}$ & $49.05 \pm 2.56^{\mathrm{c}}$ \\
\hline Brain GSH-Px $\left(\mathrm{U} \mathrm{mg}^{-1}\right)$ & $25.83 \pm 1.67^{\mathrm{b}}$ & $15.03 \pm 0.64^{\mathrm{a}}$ & $25.14 \pm 1.45^{\mathrm{b}}$ & $25.61 \pm 1.64^{\mathrm{b}}$ & $25.91 \pm 1.67^{\mathrm{b}}$ \\
\hline Brain MDA ( $\left.\mathrm{U} \mathrm{mg}^{-1}\right)$ & $5.51 \pm 0.35^{\mathrm{d}}$ & $13.25 \pm 0.59^{\mathrm{a}}$ & $10.41 \pm 0.47^{\mathrm{b}}$ & $7.62 \pm 0.46^{\mathrm{c}}$ & $7.59 \pm 0.43^{\mathrm{c}}$ \\
\hline
\end{tabular}

Values are expressed as mean $\pm \mathrm{SD}(\mathrm{n}=3)$. Means with different superscripts within a column indicate significant differences $(\mathrm{P}<0.05)$.

SOD catalyses the superoxide radicals to form hydrogen peroxide, which is subsequently decomposed to water and oxygen by GPx; this decomposition process prevents damage to membrane and biological structures (Lv et al., 2007). The SOD and GSH-Px activities in organisms decrease irreversibly with ageing; therefore, both SOD and GSH-Px are widely used to evaluate ageing (MAHMOUd \& EDENS, 2003).

MDA is one of the most known secondary products of lipid peroxidation, and typically used as indicator of oxidative damage and as ageing evaluation index; high MDA level indicates increased lipid peroxidation and oxidative damage (RoTRUCK et al., 1973; BAGCHI et al., 1995). The MDA levels in the sera and brains of the model mice significantly increased, whereas the SOD and GSH-Px activities decreased significantly compared with those of the normal group (Table $1, \mathrm{P}<0.01$ ). Intracellular free radicals in neurons accumulate with ageing, and this phenomenon decreases the ability of antioxidant defences, accelerates the 
chain reaction of lipid oxidation and exacerbates neuroinflammation (Wu et al., 2017). In the present study, the intragastric administration of GEP significantly reduced the MDA level but significantly increased the SOD and GSH-Px activities in the sera and brains of D-gal induced ageing mice as compared with those of the model group (Table $1, \mathrm{P}<0.05$ ). These results suggested that GEP can effectively suppress oxidation-induced damage to the sera and brain tissues of D-gal-induced mice; this could be due to the antioxidant activities of GEP.

\section{Conclusions}

We prepared GEP through hot water extraction and investigated its antioxidant and antiageing activities. The results showed that GEP exhibits high antioxidant activity in vitro and anti-ageing activities in D-gal-induced mice. The present results verified that GEP possesses high antioxidant and anti-ageing activities in D-gal-treated mice by facilitating antioxidant activities and attenuating lipid peroxidation.

This study was supported by the Open project of Jiangsu Marine Resources Development Research Institute (HY201601), Lianyungang science and technology planning project (JC1614), and the Priority Academic Program Development of Jiangsu Higher Education Institutions.

\section{References}

AndRews, A.T. (1986): Electrophoresis: Theory, techniques and biochemical and clinical applications. Clarendon, Oxford, pp. 53-75.

Bagchi, D., BaGchi, M., Hassoun, E.A. \& Stohs, S.J. (1995): In-vitro and in-vivo generation of reactive oxygen species DNA damage and lactate dehydrogenase leakage by selected pesticides. Toxicology, 104, 129-140.

Chen, X., CAO, D., Zhou, L., Jin, H., Dong, Q., YaO, J. \& Ding, K. (2011): Structure of a polysaccharide from Gastrodia elata B1., and oligosaccharides prepared thereof with anti-pancreatic cancer cell growth activities. Carbohydr. Polym., 86, 1300-1305.

Duh, P.D., Du, P.C. \& Yen, G.C. (1999): Action of methanolic extract of mung bean hulls as inhibitors of lipid peroxidation and non-lipid oxidative damage. Food Chem. Toxicol., 37, 1055-1061.

Hou, M.L. (2004): Food analysis. Chemical Industry Press, Beijing, China. (in Chinese).

JiANG, Y.W., LEE, J.Y. \& KIM, C.J. (2010): Anti-asthmatic activity of phenolic compounds from the roots of Gastrodia elata B1. Int. Immunopharmacol., 10, 147-154.

Kwon, J., Kim, N., Lee, D., Han, A., Lee, J.W., Seo, E., Lee, J. \& Lee, D. (2014): Metabolomics approach for the discrimination of raw and steamed Gastrodia elata using liquid chromatography quadrupole time-of-flight mass spectrometry. J. Pharm. Biomed. Anal., 94, 132-138.

Li, H.B., Wu, F., MiaO, H.C. \& Xiong, K.R. (2016): Effects of polysaccharide of Gastrodia elata Blume and electroacupuncture on expressions of brain-derived neurotrophic factor and stem cell factor protein in caudate putamen of focal cerebral ischemia rats. Med. Sci. Monit. Basic. Res. 22, 175-180.

Li, Z.F., Wang, Y.W., Ouyang, H., Lu, Y., Qiu, Y., Feng, Y.L., Jiang, H.L., Zhou, X. \& Yang, S.L. (2015): A novel dereplication strategy for the identification of two new trace compounds in the extract of Gastrodia elata using UHPLC/Q-TOF-MS/MS. J. Chromatogr. B., 988, 45-52.

Liu, M.X., Li, Q.F., LiU, Q., Huang, Z.Q. \& Qiu, F. (2009): Study on extraction technology, structure and free radical scavenging activity of polysaccharides from Gastrodia elata B1. Food Sci., 30, 29-32. (in Chinese).

Lv, L.S., Gu, X.H., TAng, J. \& Ho, C.T. (2007): Antioxidant activity of stilbene glycoside from Polygonum multiflorum Thunb in-vivo. Food Chem., 104, 1678-1681. 
Mahmoud, K.Z. \& Edens, F.W. (2003): Influence of selenium sources on age-related and mild heat stress-related changes of blood and liver glutathione redox cycle in broiler chickens (Gallus domesticus). Comp. Biochem. Phys. B., 136, 921-934.

Ming, J., Liu, J., Wu, S., Guo, X., Chen, Z. \& Zhao, G. (2012): Structural characterization and hypolipidemic activity of a polysaccharide PGEB-3H from the fruiting bodies of Gastrodia elata Blume. Procedia Eng., 37, $169-173$

Miao, H.C. \& SHEn, Y.S. (2006): Antihypertensive effect of polysaccharides subtracted from Gastrodia elata Blume. Chinese J. Hypertens., 14, 531-534. (in Chinese).

Qiao, D.L., Ke, C.L., Hu, B., Luo, J.G., Ye, H., Sun, Y., Yan, X.Y. \& Zeng, X.X. (2009): Antioxidant activities of polysaccharides from Hyriopsis cumingii. Carbohydr. Polym., 78, 199-204.

Rotruck, J.T., Pope, A.L., Ganther, H.E., Swanson, A.B., Hafeman, D.G. \& Hoekstra, W.G. (1973): Selenium: Biochemical role as a component of glutathione peroxidase. Science, 179, 588-590.

Sheng, J., Yu, F., Xin, Z., Zhaо, L., Zhu, X. \& Hu, Q. (2007): Preparation, identification and their antitumor activities in vitro of polysaccharides from Chlorella pyrenoidosa. Food Chem., 105, 533-539.

TANG, W. \& Eisenbrand, G. (1992): Gastrodia elata Bl. -in: TANG, W. \& EisEnBrand, G. (Eds) Chinese drugs of plant origin: Chemistry, pharmacology, and use in traditional and modern medicine. Springer, Berlin, pp. 545-547.

Wu, S.J., Lu, M.S. \& WANG, S.J. (2017): Anti-aging activities of the water soluble chitosan from Clanis bilineata larvae. Int. J. Biol. Macromol., 102, 376-379.

YAO, X.C., CAO, Y. \& WU, S.J. (2013): Antioxidant activity and antibacterial activity of peach gum derived oligosaccharides. Int. J. Biol. Macromol., 62, 1-3.

Zhang, C., GaO, Z., Hu, C.L., Zhang, J.J., Sun, X.Y., Rong, C.B. \& JiA, L. (2017): Antioxidant, antibacterial and anti-aging activities of intracellular zinc polysaccharides from Grifola frondosa SH-05. Int. J. Biol. Macromol., 95, 778-787. 